\title{
Translation and cultural adaptation of the Nurse Professional Competence Scale: The NPC Scale - German AUT language version
}

\author{
Jan Daniel Kellerer*1, Matthias Rohringer ${ }^{1}$, Isabella Theresia Raab² ${ }^{2}$, Gerhard Müller ${ }^{1}$, Daniela Deufert ${ }^{1}$ \\ ${ }^{1}$ UMIT - Private University for Health Sciences, Medical Informatics and Technology, Austria \\ ${ }^{2}$ City Hospital Triemli, Zurich, Switzerland
}

Received: August 25, 2020

DOI: $10.5430 /$ jnep.v11n1p51
Accepted: September 9, 2020

Online Published: September 24, 2020

\begin{abstract}
Assessing nursing-related competences becomes increasingly relevant. Therefore, psychometrically tested and contentual appropriate instruments are needed. The Nurse Professional Competence (NPC) Scale seems convenient to assess nurses' competences in German-speaking countries. This article describes the translation and cultural adaption of the NPC Scale English-language version for the German-speaking linguistic area of Austria (AUT), following the respective principles defined by the International Society for Pharmaoeconomics and Outcome Research (ISPOR). The aim was to provide a German-language version of the NPC Scale usable for the Austrian specific linguistic and cultural area. Due to polydimensionality of the scale and the extensive number of items being stepwise revised by researchers, several innovative methodological approaches were required to ensure transparent and comprehensible decision-making, data-revision and consensus-gainig throughout the overall process. Useful methods are presented to cope with challenges accompanying the coverage of decentralized data-revision and consensus-finding within the translation and cultural adaption of a polydimensional scale with a high number of items. The Nurse Professional Competence Scale, 88 items - German Austrian language version is conceptually, semantically and idiomatically equivalent compared to the NPC Scale original version and is recommendable for the usage in the target country's nursing context from a linguistic point of view.
\end{abstract}

Key Words: NPC Scale, Nurse professional competence scale; Austria, Translation, Cultural adaption, ISPOR

\section{INTRODUCTION}

The assessment and display of nurses' competences is getting increased political interest since nursing education is enhanced from vocational programs to academic programs in Austria. ${ }^{[1]}$ Thus, the acknowledgement of informally and non-formally evolved competences to facilitate access to tertiary education is politically demanded and vital for the development of the professionalization of nursing. ${ }^{[2]} \mathrm{Com}-$ petence appears as reflexive, creative problem-solving in complex, selective meaningful situations. ${ }^{[3]}$ As reflexive and self-organized acting in a complex working field is a basic requirement for nurses, ${ }^{[4]}$ developed competences must been taken into account plausibly to make its influence on the quality of care ${ }^{[5]}$ countable and hence boost the development of nursing. Therefore, appropriate psychometrically tested instruments must be provided. ${ }^{[6]}$ The results of a previous literature research showed a lack of valid and reliable instruments for the assessment of registered nurses' competences

\footnotetext{
* Correspondence: Jan Daniel Kellerer; Email: jan.kellerer@umit.at; Address: UMIT - Private University for Health Sciences, Medical Informatics and Technology, Austria.
}

Published by Sciedu Press 
in Austria. A total of five holistic instruments for assessing nursing competence in the European Economic Area were identified. However, only the items of the Nurse Professional Competence (NPC) Scale ${ }^{[7]}$ fully correspond to the competence clusters defined by Austrian law. ${ }^{[8]}$ This scale was therefore considered appropriate for assessing nursing competence in Austria. ${ }^{[9]}$ The NPC Scale is a self-assessment tool for the holistic assessment of professional nurses' competences. It consists of a total of 88 items, which can be assigned to the eight dimensions of nursing care (15 items), value-based nursing care ( 8 items), medical/technical care (10 items), teaching/learning and support (11 items), documentation and information technology (4 items), legislation in nursing and safety planning (9 items), leadership in and development of nursing care (26 items), and education and supervision of staff/students (5 items). ${ }^{[7]}$ Construct validity was tested by exploratory principal component analysis, the eight extracted factors explain $48 \%$ of the total variance. Discriminant validity was confirmed by a known-group comparison which revealed significant differences between the compared groups. The results of the internal consistency testing confirm the reliability of the scale (Cronbach's alpha values ranging from 0.75 to 0.94 for single factors and 0.97 for the entire scale). ${ }^{[7]}$ The NPC Scale has been translated from Swedish into English ${ }^{[10]}$ language on the basis of WHO process of translation and adaptation of instruments. ${ }^{[11]}$

For the prospective use of the instrument in the Austrian nursing context, a translation and cultural adaptation was required. ${ }^{[12]}$ The methodological approaches to the translation and adaptation of questionnaires are manifold. It is commonly recommended that the instrument translation undergoes a forward and backward translation process, ${ }^{[13]}$ the cultural adaptation for the target population is also described as essential. ${ }^{[11,14-16]}$

In the process of translation, care must be taken to meet the criteria of a high-quality translation as stated by Acquadro, Conway, Haarendran and Aaronson. ${ }^{[17]}$ With regard to the translation and cultural adaptation of instruments, there is no gold standard for the methodological approach. ${ }^{[18]}$ In regard to the high number of items to be translated and their partial linguistic and conceptual complexity and the subsequent extensive effort in terms of data, resource and time management, the procedural approach following the ISPOR principles $^{[15]}$ was chosen. This procedure consists of ten process steps, which describe in detail the development of the translation and adaptation process. Our article further presents measures to increase traceability and transparency in consensual decision-making throughout the translation and adaptation process.

\section{METHODS}

In the following, the methodical procedure of the translation process based on the ISPOR principles is described and the methods of communication used as well as data collection and data evaluation are described. Figure 1 gives a graphical overview of the successive process steps. It shows the required tasks in the individual ten process steps as well as the persons involved in the consensual decision-making process.

\subsection{Expert panel}

One person was named as a key person for the Austrian language area and this formed the expert panel together with another expert (see Table 1).

\subsection{Translators and external experts}

The forward and backward translation of the NPC Scale involved both professional translators without professional nursing background and translators who came from areas of professional nursing and who had excellent language skills in the respective target language. Table 2 gives an overview of the characteristics of the contributors at the different translation steps. It also lists the original developers of the scale involved in the translation process and an external expert.

\subsection{Sample of cognitive debriefing}

The inclusion criterion for participation in the evaluation of the German Austrian language version of the NPC Scale was a completed education in health and nursing (vocational or academic education). Thus, the requirement that the target group for which the instrument was designed should be used as experts for the assessment of comprehensibility should be fulfilled. A total of 17 respondents took part in the cognitive debriefing.

\subsection{Instruments used in the translation process 2.4.1 Forward translation}

Each translator received a manual that provided information about the project background and included the NPC Scale in English and Swedish language (Translator 1 only, see Table 2). Additional information regarding the methodological approach of the translation process and the theoretical construct of the NPC Scale were given. It was also agreed that any translation that appeared problematic (in terms of words, meaning and concepts) should be documented in detail.

\subsubsection{Back translation}

Each translator received the first German Austrian language version of the scale, constructed on the basis of the forward translations. The translators were instructed to comment on any translation that appeared problematic ("word-, meaning-, and concept-related") and to describe the existing problems. 


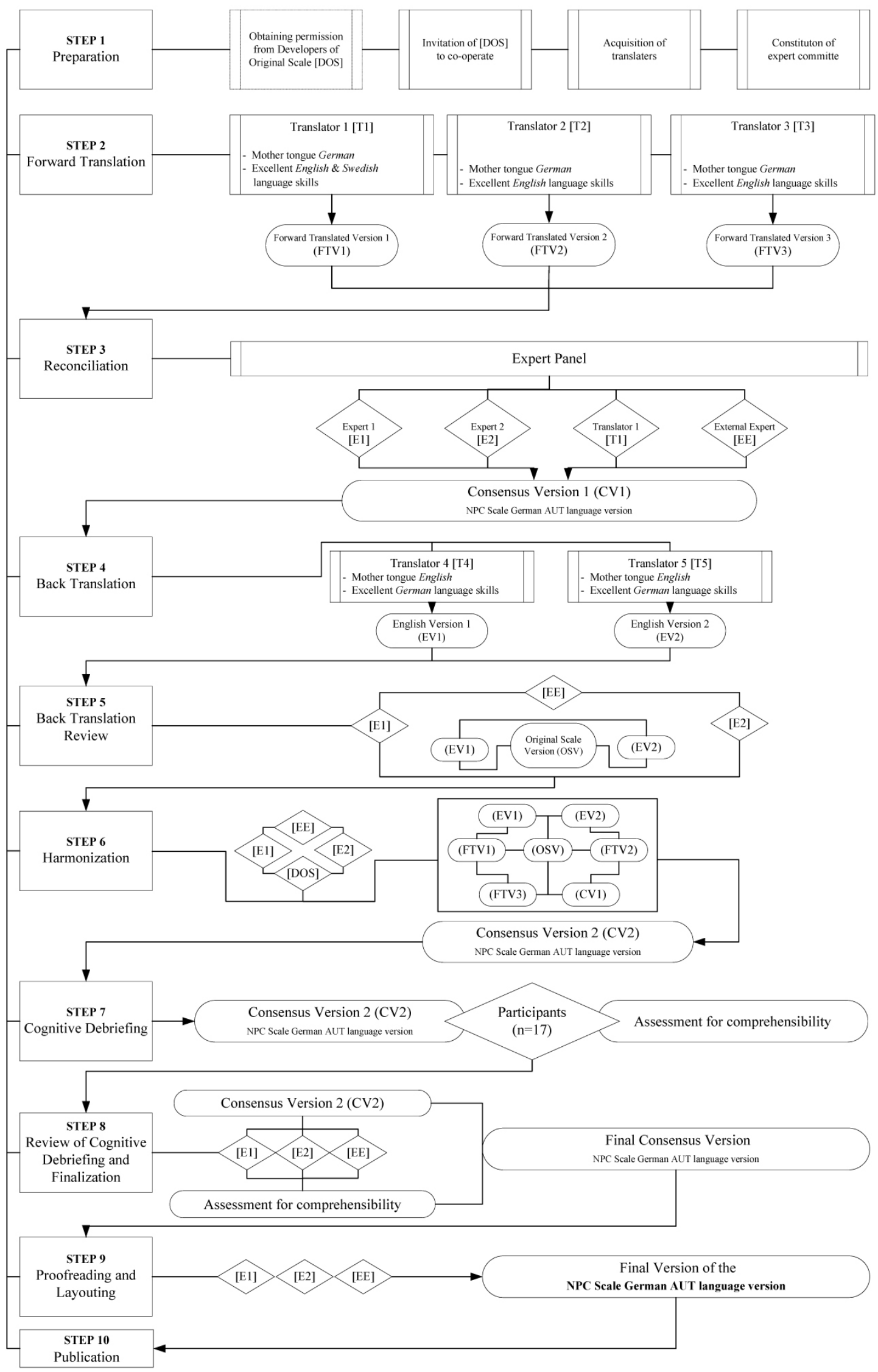

Figure 1. Presentation of the step-by-step translation and cultural adaptation of the NPC Scale 
Table 1. Characteristics of expert panel members

\begin{tabular}{lll}
\hline Experts & $\begin{array}{l}\text { Present Professional } \\
\text { Activity }\end{array}$ & $\begin{array}{l}\text { Work Experience in } \\
\text { Nursing Context }\end{array}$ \\
\hline \multirow{2}{*}{ Expert 1 } & Senior scientist & $\begin{array}{l}\text { Registered nurse (20 years) } \\
\text { Nursing scientist (14 years) }\end{array}$ \\
Expert 2 & Junior scientist & $\begin{array}{l}\text { Registered nurse (14 years) } \\
\text { Nursing scientist (5 years) }\end{array}$ \\
\hline
\end{tabular}

\subsubsection{Harmonization}

All translated scale versions as well as the first consensus version were sent to the original authors. The Swedish original authors had the opportunity to communicate comments and criticism in written form. In addition, a face-to-face meeting between a member of the panel of experts and the original authors was held to discuss open questions and problems and to propose solutions.

Table 2. Characteristics of the contributors per process step

\begin{tabular}{|c|c|c|c|c|c|}
\hline Contributory Function & ISPOR-Process Step & $\begin{array}{l}\text { Mother } \\
\text { Tongue }\end{array}$ & $\begin{array}{l}\text { Foreign } \\
\text { Language }\end{array}$ & $\begin{array}{l}\text { Target Language } \\
\text { Proficiency }\end{array}$ & $\begin{array}{l}\text { Nursing } \\
\text { Context }\end{array}$ \\
\hline Translator 1 & Forward translation, Harmonization & de & en, sv & excellent ${ }^{\#}$ & no \\
\hline Translator 2 & Forward translation & de & en & excellent & yes \\
\hline Translator 3 & Forward translation & de & en & excellent $^{\#}$ & no \\
\hline Translator 4 & Backward translation & en & de & excellent $^{\#}$ & no \\
\hline Translator 5 & Backward translation & en & de & excellent & yes \\
\hline Developer of original Swedish scale & Review, Harmonization & sv & en, de & good & yes \\
\hline External Expert & Harmonization, Finalization & sv & en, de & excellent & yes \\
\hline
\end{tabular}

Note. de = German; en = English; sv = Swedish; ; ${ }^{\#}$ = Professional translator

\subsubsection{Cognitive debriefing}

Before the consensus version was assessed for comprehensibility, the participants in the cognitive debriefing received information on the background and objectives of the translation project and a declaration that participation was voluntary. They were instructed to assess each item in terms of comprehensibility in terms of both wording and meaning. For this purpose, the participants were given an evaluation sheet in which there was space next to each of the 88 items for specific comments and remarks. The completed assessment sheets were then returned anonymously to the project team.

\subsection{Accompanying controlling and analysis of the pro- cess steps}

All consensus meetings of the expert group as well as discussions with external experts and translators were recorded via WebEx ${ }^{\circledR}$. All translations, including the written comments of the respective translators, as well as memos from the expert discussions, were transferred into a matrix created in MS Excel ${ }^{\circledR}$. Subsequently, the audio recordings (WebEx ${ }^{\circledR}$ ) of the consensus sessions were linked to the respective edited items. Since the comparison of the individual translation versions of the scale could only be carried out in several stages due to the range of 88 items and thus a large body of information and data had to be handled within the expert group, the audio recordings of the consensus sessions were deductively classified using a coding system. This coding system was also used to analyse the written data from the comments of the translators and the original authors, as well as the comments of the participants in the cognitive debriefing. The codings were defined according to the equivalence forms (conceptual, semantic, idiomatic and experiential equivalence) of Beaton, Bombardier, Guillemin and Ferraz. ${ }^{[19]}$

\subsection{Ethical considerations}

According to the estimation of the Research Committee for Scientific and Ethical Questions (RCSEQ) of UMIT-Private University of Health Sciences, Medical Informatics and Technology, Hall in Tyrol, ethical appraisal has not been necessary. Raters participated voluntarily in the study and written informed consent was obtained prior to participation.

\section{RESULTS}

The results of the corresponding ISPOR process steps are presented below.

\subsection{Preparation}

First we obtained the permission of the developers of the scale for translation and adaptation. In the course of this, the willingness of the original developers to co-operate was confirmed and their consultative support in the project was negotiated. Suitable translators were acquired and informed about the project schedule. Finally, the responsible key person for Austria was named and the expert committee was constituted. 


\subsection{Forward translation}

A total of three forward translations were prepared. The respective translators made comments in the course of the translation regarding unclear wording or unclear meanings. The concept of 23 items was unclear, the semantic equivalence of 55 items was problematic.

\subsection{Reconciliation}

The forward translated scale versions were reviewed and compared in the expert panel. If required, the translators were contacted and involved in the discussion. As it was found that the English scale already showed differences in the item formulations compared to the original Swedish scale, the translator with an excellent command of both languages was included in the expert discussion. This was done in an attempt to resolve uncertainties regarding the concepts underlying the respective items and to ensure close agreement in word and meaning with the original (Swedish) scale version. A preliminary Austrian-language consensus version was developed, whereby the wording of 15 items was still categorized by the panel of experts as rather critical, while for 4 items strong doubts remained regarding the adequate translation.

\subsection{Back translation}

On the basis of the first consensus version, the retranslation into English was carried out. For 12 items the translators stated ambiguities regarding semantic equivalence, the underlying concept was declared insufficiently comprehensible for 4 items.

\subsection{Back translation review}

In a further expert discussion, the back-translated scale versions were compared with the English language scale. It was found that those items that had already been classified as critical in the course of the conception of the first consensus version also revealed both semantic and conceptual problems in the course of the back translation.

\subsection{Harmonization}

In the course of the harmonization step, all scale versions translated up to that point were compared and discussed, including the first consensus version, the English scale version and occasionally the Swedish scale version. Unclear concepts and semantic discrepancies were discussed with the original authors. As a result of this process step, 80 items could be finally classified as uncritical. For 8 items, doubts remained regarding conceptual and semantic equivalence in the harmonized German Austrian language translation.

\subsection{Cognitive debriefing}

A total of 17 nurses took part in the assessment of the harmonized German Austrian language scale version in terms of comprehensibility. They criticized 27 items as incomprehensible in terms of concept, 29 items as incomprehensible in terms of semantic comprehensibility and one item which pointed to an idiomatic equivalence problem. Furthermore, they cited several errors in grammar and spelling.

\subsection{Review of cognitive debriefing results and finaliza- tion}

The comments and critiques from the Cognitive Debriefing were processed in a final expert discussion and the translation was adapted accordingly. In order to make the adaptation process as consistent as possible, both an external expert (see Table 2) and the translators were involved. As no consensus could be found within the expert group regarding 10 critical items, these items were discussed with the authors of the original scale and solutions were agreed upon. Finally, the translated scale was proofread for spelling and grammar and finalized.

\section{Discussion}

The methodical approach according to the process steps in accordance with the ISPOR principles ${ }^{[15]}$ has proven to be appropriate. Thus it was possible to ensure that linguistic, but above all cultural aspects were sufficiently taken into account when translating an instrument and that biases of the construct could be detected. ${ }^{[20]}$ According to Wild et al., ${ }^{[15]}$ it is advisable to decide before the translation process begins whether the aim of the translation is to generate an instrument in an as syntactically-semantically identical language as possible, or whether conceptual equivalence is the primary consideration. In order to accurately reproduce the theoretical construct of the NPC Scale and the underlying concepts of the individual items in the target language, a conceptual translation was preferred to a syntactic-semantic one. This proved to be effective because the theoretical construct of the NPC Scale is subject to strong subject-specific interpretation variances due to the many ways in which key terms like caring, nursing and competence can be understood and interpreted.

As the instrument's name suggests, its aim is to assess competence. However, in the English version of the scale, the initial question is formulated as "Do you think you have the ability to...". Ability is already a very unspecific term in English, and the possible translations in German are also diverse. ${ }^{[21]}$ The German term Fähigkeit proposed by the translators is a linguistically correct translation of the English term ability. However, the term ability seems insufficiently suited to 
reflect the definitional theoretical meaning of competence, since ability is theoretically only the prerequisite for competence. ${ }^{[22]}$ Ultimately, taking into account the data collected in the process step of cognitive debriefing, the concept of ability was nevertheless judged to be appropriate since this term was not criticised by the participants in the cognitive debriefing and can thus be regarded as a suitable synonym for the target group of the instrument. Another problematic term in the context of the translation was the English term caring. This term already has many meanings in English and is interpreted differently even in the context of nursing care. ${ }^{[23,24]}$ This discrepancy became apparent in the evaluation of the (forward) translated German Austrian language scale versions. The two translators without professional nursing-related background used both the German-language term Zuwendung and the term Betreuung, while the translator with professional nursing-related background retained the term as Anglicism, arguing that caring was a commonly used technical term within the target group. This example showed that the inclusion of professional translators from outside the nursing profession significantly broadened the nursing perspective in the discussion about the correct translation and interpretation of technical terms. The recognition of the added value of this criterion is in line with the statement by Beaton et al. ${ }^{[19]}$ that the quality of the translation increases if at least one translator is involved who does the translation without a (nursing) professional background and uninfluenced by context-specific knowledge. The clarification of the actual contextual meaning could be clarified in consultation with the original authors, as suggested by Wild et al. ${ }^{[15]}$

During the translation process it often became apparent how essential this constant exchange with the original authors of an instrument is. Another example for the relevancy of the cooperation is the discussion about an item referred to "safeguarding aesthetic aspects of the care environment". Depending on the contextual interpretation and on the specific previous knowledge of the persons involved in the translation, this term can be associated with art in the general sense on the one hand, and with art in the sense of the art of nursing on the other hand, ${ }^{[25]}$ as well as with the nursing specific concept of aesthetics in nursing practice. ${ }^{[26]}$

Decision-making within the group of experts can thus be made more difficult by the fact that each of the experts attributes an implicit meaning to the term, ${ }^{[27]}$ which can distort the original statement. It is therefore essential to promptly clarify relevant discrepancies in the translation process with the original developers of the instrument in order to prevent incorrect translations.
The methodological analysis in the form of reference to a deductive category system proved to be helpful for the project group in structuring the large body of different data and information and thus being able to disclose the translation process in a transparent and traceable manner. This showed that translations of items that had already caused dissent within the expert discussions were also criticized in the target population during the cognitive debriefing. The categories formed on the basis of the equivalence forms defined by Beaton et al. ${ }^{[19]}$ offered the project team the opportunity to clearly identify conceptual, semantic and idiomatic ambiguities, to reflect on decisions where necessary, and thus to articulate and correct errors in a focussed manner. Although there is demand for the transparent documentation of the translation process as a quality feature, ${ }^{[12]}$ no methodological procedure is yet proposed for evaluating the expert discussions or the critical statements from the cognitive debriefing within the target population.

Translation-specific decisions therefore remain intransparent and the quality of the translation is consequently difficult to assess. ${ }^{[18]}$ The content analysis procedure conceived in this paper could be considered as a useful method to increase the transparency of the translation process.

It remains critical that for economic and organisational reasons the English scale version was used for the translation of the NPC Scale into the target language. In the course of the translation process at hand, uncertainties occurred regarding the actual meaning of individual terms or items, as the scale translated into English already differed significantly from the Swedish original, both conceptually and semantically. A translator with excellent knowledge of both English and Swedish participated in the translation of the scale into German Austrian language. Due to the lack of nursing context of this translator, however, it was difficult to process terms specific to the nursing subject and their item-specific meanings. As a result, it was likely that the German Austrian language scale version would diverge from the Swedish original. In order to minimize this bias, the final version of the NPC Scale was submitted for final evaluation to a Swedish native-speaking expert (see Table 2) with a professional nursing background and excellent knowledge of German and English, who assessed the translation as consistent.

\section{Conclusion}

The translation and cultural adaptation of an instrument with such a high number of items and a theoretical construct, which requires enormous prior knowledge of the content due to its multidimensionality, can only be carried out within a strict time, organisational and methodological framework. In addition, it requires appropriate technical and method- 
ological possibilities to organize, structure and analyse the enormous amounts of data from the expert discussions, as well as the written records and received feedback from the participants. The systematic approach, taking into account the content analytical method of deductive category structuring, has proven to be helpful. Since assessment instruments will continue to play a major role for the nursing profession in the future and their high-quality translation into the corresponding target language is the basis for a confident usage, the development of suitable accompanying methods within the translation process is fundamental for the traceability of decisions made and the evaluation of the translation process. As the literature does not contain any guidelines or recommendations regarding methodological process docu-

\section{REFERENCES}

[1] Schaeffer D. Professionalisierung der Pflege - Verheißung und Realität. GuS. 2011; 65(5-6): 30-7. https ://doi .org/10.5771/16 11-5821-2011-5-6-30

[2] Reichardt C, Wernecke F, Giesler M, et al. Psychometrische Erfassung von Kompetenzen am Beispiel von Studierenden und Auszubildenden der Pflege. Pflege. 2016; 29(5): 257-65. PMid:27239742 https://doi.org/10.1024/1012-5302/a000492

[3] Erpenbeck J, Rosenstiel L von, Grote S, et al. Handbuch Kompetenzmessung: Erkennen, verstehen und bewerten von Kompetenzen in der betrieblichen, pädagogischen und psychologischen Praxis. 3rd ed. Stuttgart: Schäffer-Poeschel; 2017. 734 p. https: //doi.org/10.34156/9783791035123

[4] Austrian Federal Ministry for Digital and Economic Affairs. Bundesgesetz über Gesundheits- und Krankenpflegeberufe (Gesundheits- und Krankenpflegegesetz GuKG) [Internet] [cited 2019 Dec 16]. Available from: https://www.ris.bka.gv.at/GeltendeFassung.wxe? Abf rage=Bundesnormen\&Gesetzesnummer $=10011026$

[5] Benner PE. Stufen zur Pflegekompetenz $=$ From novice to expert: From novice to expert. 3rd ed. Bern: Hogrefe; 2017. 336 p. ger.

[6] Darmann-Finck I, Reuschenbach B. Entwicklungsstand der Kompetenzmessung im Berufsfeld Pflege [Current state of competence assessment in nursing]. Z Evid Fortbild Qual Gesundhwes. 2013; 107(1): 23-9. ger. PMid:23415340 https://doi.org/10.1016/ j.zefq. 2012.11.020

[7] Nilsson J, Johansson E, Egmar AC, et al. Development and validation of a new tool measuring nurses self-reported professional competence-the nurse professional competence (NPC) Scale. Nurse Educ Today. 2014; 34(4): 574-80. PMid:23938092 https://doi. org $/ 10.1016 /$ j.nedt .2013 .07 .016

[8] Austrian Federal Ministry for Digital and Economic Affairs. Verordnung der Bundesministerin für Gesundheit, Familie und Jugend über Fachhochschul-Bachelorstudiengänge für die Ausbildung in der allgemeinen Gesundheits- und Krankenpflege (FHGesundheits- und Krankenpflege-Ausbildungsverordnung - FHGuKAV). BGB1. II Nr. 200/2008 [Internet] [cited 2019 Dec 16]. Available from: https://www.ris.bka.gv.at/Dokument.wxe?Abfrage $=$ Bundesnormen\&Dokumentnummer $=$ NOR30006508 mentation and its evaluation, there is a need for research in this area.

\section{ACKNOWLEDGements}

We would like to thank a scientific expert working group of the European Network of Nursing Academies e.V. (ENNA) (www.en-na.eu), which developed the first German language version of the NPC Scale. Moreover, we would like to thank the members of the NPC Research Group for their support during the entire translation process. If there is any interest in the NPC Scale, we recommend to visit the website www.npcresearchgroup.com for any further information.

\section{CONFLICTS OF INTEREST Disclosure}

The authors declare that there is no conflict of interest.
[9] Kellerer JD, Raab I, Müller G, et al. Identifikation valider und reliabler Instrumente zur Einschätzung der Kompetenzen professionell Pflegender in Österreich. PFLEGEWISSENSCHAFT. 2018; 20(1/2): 24-38.

[10] Nilsson J, Gardulf A, Lepp M. Process of translation and adaptation of the Nurse Professional Competence (NPC) Scale. JNEP. 2015; 6(1). https://doi.org/10.5430/jnep.v6n1p100

[11] World Health Organization. WHO I Process of translation and adaptation of instruments [Internet]. 2020 [updated 2020 Aug 19; cited 2020 Aug 19]. Available from: https://www.who.int/substa nce_abuse/research_tools/translation/en/

[12] Reuschenbach B, Mahler C. Pflegebezogene Assessmentinstrumente: Internationales Handbuch für Pflegeforschung und -praxis. 1st ed. s.1.: Verlag Hans Huber; 2011. 632 p. ger.

[13] Epstein J, Santo RM, Guillemin F. A review of guidelines for crosscultural adaptation of questionnaires could not bring out a consensus. Journal of Clinical Epidemiology. 2015; 68(4): 435-41. PMid:25698408 https://doi.org/10.1016/j.jclinepi. 201 4.11 .021

[14] Sperber AD. Translation and validation of study instruments for crosscultural research. Gastroenterology. 2004; 126(1 Suppl 1): S1248. PMid:14978648 https://doi.org/10.1053/j.gastro. 200 3.10 .016

[15] Wild D, Grove A, Martin M, et al. Principles of Good Practice for the Translation and Cultural Adaptation Process for Patient-Reported Outcomes (PRO) Measures: report of the ISPOR Task Force for Translation and Cultural Adaptation. Value Health. 2005; 8(2): 94 104. PMid:15804318 https://doi.org/10.1111/j.1524-473 3.2005.04054.x

[16] Wang WL, Lee HL, Fetzer SJ. Challenges and strategies of instrument translation. West J Nurs Res. 2006; 28(3): 310-21. PMid:16585807 https://doi.org/10.1177/0193945905284712

[17] Acquadro C, Conway K, Hareendran A, et al. Literature review of methods to translate health-related quality of life questionnaires for use in multinational clinical trials. Value Health. 2008; 11(3): 509-21. PMid:18179659 https : //doi .org/10.1111/j.1524-4733.20 $07.00292 . x$ 
[18] Maneesriwongul W, Dixon JK. Instrument translation process: a methods review. J Adv Nurs. 2004; 48(2): 175-86. PMid:15369498 https://doi.org/10.1111/j.1365-2648.2004.03185.x

[19] Beaton DE, Bombardier C, Guillemin F, et al. Guidelines for the process of cross-cultural adaptation of self-report measures. Spine. 2000; 25(24): 3186-91. PMid:11124735 https ://doi.org/10.1 097/00007632-200012150-00014

[20] van de Vijver F, Hambleton RK. Translating Tests. European Psychologist. 1996; 1(2): 89-99. https://doi.org/10.1027/1016 $-9040.1 .2 .89$

[21] Wirtz MA. Dorsch - Lexikon der Psychologie. 19th ed.; 2020. 2032 p. ger.

[22] Paschen M, Fritz A, editors. Die Psychologie von Potenzial und Kompetenz: Individuelle Stärken verstehen, beurteilen und entwickeln. Neustadt an der Aisch: Schmidt; 2014. 497 p. ger.
[23] Swanson KM. Empirical development of a middle range theory of caring. Nurs Res. 1991; 40(3): 161-6. https://doi.org/10.109 7/00006199-199105000-00008

[24] Benner PE, Wrubel J. The primacy of caring: Stress and coping in health and illness. 425 p. eng.

[25] Robinson SG. True presence: practicing the art of nursing. Nursing. 2014; 44(4): 44-5. PMid:24646578 https ://doi.org/10.1097/ 01.NURSE. 0000444533.58704. e5

[26] Koithan MS. Aesthetics in nursing practice and education. Issues Ment Health Nurs. 1996; 17(6): 529-39. PMid:9052092 https : //doi.org/10.3109/01612849609006531

[27] Larson ML. Meaning based translation: A guide to cross language equivalence. 2nd ed. Lanham, Md.: Univ. Press of America; 1998. 586 p. eng. 